\title{
Variable Stiffness Spar Wind-Tunnel Model Development and Testing
}

\author{
James R. Florance*, Jennifer Heeg ${ }^{\dagger}$, Charles V. Spain ${ }^{\ddagger}$, \\ Thomas G. Ivanco ${ }^{\S}$, and Carol D. Wieseman ${ }^{\top}$ \\ NASA Langley Research Center, Hampton, VA 23681 \\ Peter S. Lively" \\ Lockheed Martin Space Operations, Hampton, VA 23681
}

\begin{abstract}
The concept of exploiting wing flexibility to improve aerodynamic performance was investigated in the wind tunnel by employing multiple control surfaces and by varying wing structural stiffness via a Variable Stiffness Spar (VSS) mechanism. High design loads compromised the VSS effectiveness because the aeroelastic wind-tunnel model was much stiffer than desired in order to meet the strength requirements. Results from tests of the model include stiffness and modal data, model deformation data, aerodynamic loads, static control surface derivatives, and fuselage standoff pressure data. Effects of the VSS on the stiffness and modal characteristics, lift curve slope, and control surface effectiveness are discussed. The VSS had the most effect on the rolling moment generated by the leading-edge outboard flap at subsonic speeds. The effects of the VSS for the other control surfaces and speed regimes were less. The difficulties encountered and the ability of the VSS to alter the aeroelastic characteristics of the wing emphasize the need for the development of improved design and construction methods for static aeroelastic models. The data collected and presented is valuable in terms of understanding static aeroelastic wind-tunnel model development.
\end{abstract}

\section{Introduction}

$\mathbf{H}$ IGH maneuverability and stealth under wide ranges of critical flight conditions are required for modern fighter and military aircraft. A more flexible aircraft with optimum application of the control systems is often the result of the design goal. This goal can be achieved through developments in multidisciplinary optimization procedures, digital flight control systems, and the adaptive-structure technologies. These technologies can be used in combination to aeroelastically manipulate aerodynamic loads that result in favorable static/dynamic responses of an aircraft to achieve the required maneuver performance, while improving the drag performance and reducing structural weight. ${ }^{1}$

In the mid-1980's, Rockwell International Corporation developed a concept called the Active Flexible Wing (AFW), which exploited wing flexibility to improve maneuver performance and reduce weight. The AFW design allowed a fixed amount of aeroelastic twist with the use of multiple leading- and trailingedge control surfaces to improve roll performance up to and beyond control surface reversal. ${ }^{2,3}$ The Variable

\footnotetext{
*Aerospace Engineer, Senior Member AIAA.

${ }^{\dagger}$ Senior Research Engineer, Senior Member AIAA.

${ }_{\ddagger}$ Senior Research Engineer.

$\S_{\text {Aerospace Engineer. }}$

ISenior Research Engineer, Associate Fellow AIAA.

$\|$ Senior Engineer.

This paper is a work of the U.S. Government and is not subject to copyright protection in the United States.
}

Stiffness Spar (VSS) concept looks to extend the applicability of the AFW concept by not only employing multiple control surfaces, but also varying the structural stiffness of the wing. ${ }^{1}$

The VSS wind-tunnel model was funded under an Air Force Small Business Innovative Research project with goals aligned with the joint NASA, Air Force, and industry program known as the Active Aeroelastic Wing (AAW) Flight Research Program. The AAW Program is researching technologies that exploit wing aeroelastic flexibility for a net benefit and is flight testing those technologies on an F/A-18 with modified wings that allow greater flexibility than on current production F/A-18's. ${ }^{4}$ A static-aeroelastically scaled wind-tunnel model of the AAW flight vehicle was developed to correlate data from the wind-tunnel and flight tests and to advance aeroelastic model design methods. An F/A-18 configuration was chosen for the VSS model which allows it to share some AAW wind-tunnel model hardware. The VSS main wing and control surfaces were mated to the AAW model's fuselage and empennage.

The VSS concept was developed by Zona Technologies, Inc. This concept would allow the maneuvering of an aircraft using a minimum number of aerodynamic control surfaces. A structural element governing the stiffness and elastic axis position of the main wing box would allow modification of the static aeroelastic control surface effectiveness at different flight conditions. The purpose of the VSS wind-tunnel test in the NASA Langley Transonic Dynamics Tunnel (TDT) is to in- 
vestigate the feasibility of a such concept.

This paper presents the analysis, model construction, testing, and results from the TDT wind-tunnel test of a VSS concept model. The primary objectives of the wind-tunnel test were to acquire data for validation of the variable stiffness spar design methodologies and tools, and to experimentally demonstrate one realization of the VSS concept. The primary challenges involved in design, fabrication, and testing of this model included meeting strength requirements while maintaining torsional flexibility, developing a buildable mechanism with the power to affect the wing aeroelastic characteristics, and the complexity of all the measurement and control systems.

\section{Facility Description}

The NASA Langley Transonic Dynamics Tunnel (TDT) is a continuous-flow, variable-pressure wind tunnel with control capability to independently vary Mach number and total pressure and to regulate total temperature. The test section is $16 \mathrm{x} 16$ feet with cropped corners, making the cross-sectional area approximately $248 \mathrm{ft}^{2}$. The floor and ceiling of the test section are axially slotted to allow a continuous variation of test section Mach number up to about 1.2. A more detailed description of the tunnel test section geometry is available in reference 5. The tunnel is capable of operating at total pressures from nearvacuum to atmospheric pressure in air or in a heavy gas (1,1,1,2-Tetrafluoroethane, also known as R-134a). Advantages of R-134a as a test medium are its density, which is almost four times that of air, and its speed of sound, which is about half that of air. These properties of R-134a ease both aeroelastic scaling concerns and energy requirements for the facility. It is this combination of large scale, variable pressure, high speed, and high density that makes the TDT ideally suited for testing aeroelastically scaled models. References 6 and 7 describe in greater detail the features of the facility and the various types of tests recently conducted in the TDT.

\section{Model Description}

The VSS wind-tunnel model is a $26 \%$ geometrically scaled right half-span representation of an F/A-18A. The main fuselage of the model is assembled with fiberglass skins over an internal aluminum framework. The fuselage incorporates a 2.5-inch wide standoff to move the model out of the tunnel wall boundary layer. The leading edge extension and engine inlet are machined from a medium-low density, syntactic polyurethane board called Renshape 440. The flow-through duct is formed from stereolithography resin that is wrapped with fiberglass to provide the required strength. The horizontal and vertical tails are machined from solid aluminum and are secured to the fuselage internal structure.

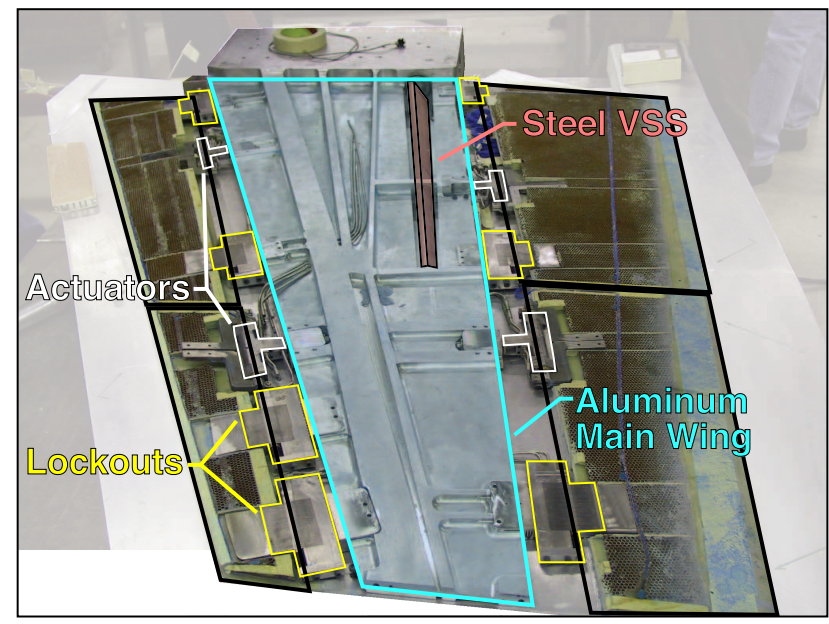

Fig. 1 Photo of wing lower surface showing the internal aluminum structure, steel VSS, and control surface attachments.

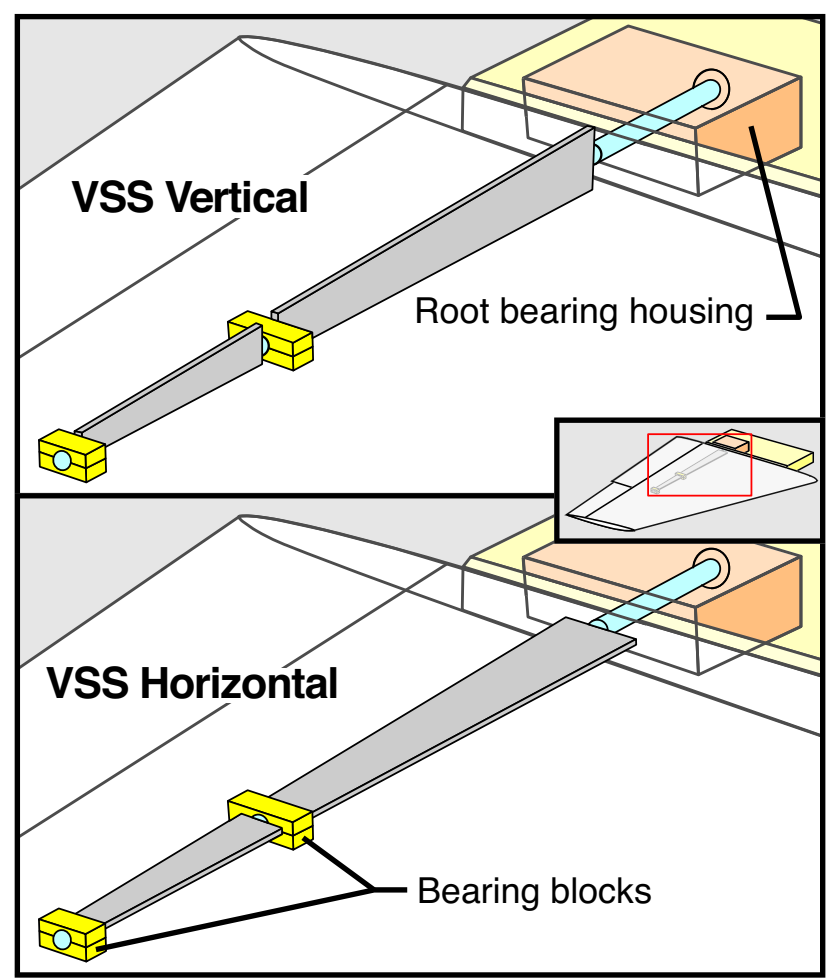

Fig. 2 Sketches of the VSS in the vertical and horizontal orientations.

The main wing structure is machined from a large 7075-T651 aluminum billet with multiple spanwise spars as shown in figure 1 . The wing incorporates a spar with a rectangular cross-section that is used to change the wing bending and torsional stiffness as it is rotated from a vertical (wing stiffer) to a horizontal (wing softer) position. The spar is machined from 13-8PH stainless steel and rotated using a hydraulic actuator. The spar is shown in the horizontal and vertical positions in figure 2. The spar span is roughly $58 \%$ of the wing span and is located at approximately $60 \%$ wing chord. The spar is attached to the wing 


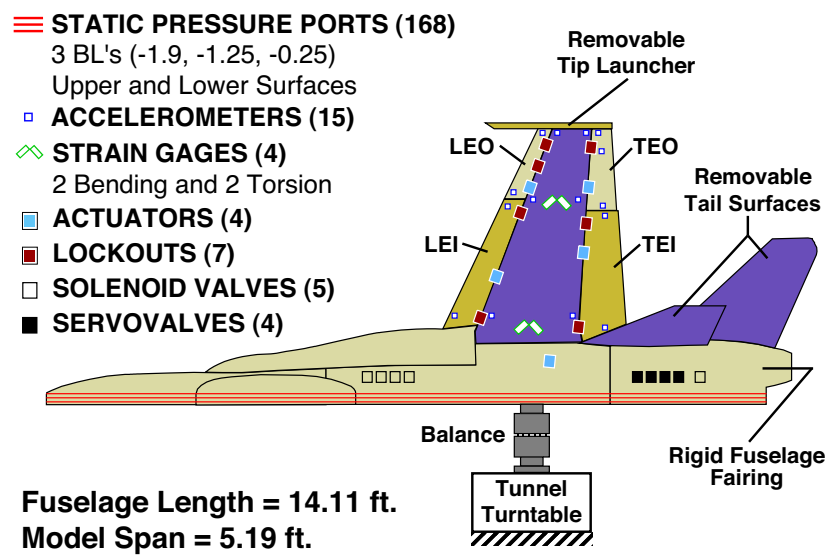

Fig. 3 Schematic of model configuration and instrumentation layout.

through bearings at the spar root, 2/3-span, and tip.

A balsa wood covering is bonded to the upper and lower surfaces of the main wing structure to provide the proper airfoil shape. The balsa wood is covered by a thin layer of fiberglass to provide a smooth outer surface while minimizing its effects on stiffness.

The model has four control surfaces, a leading edge outboard (LEO) flap, a leading edge inboard (LEI) flap, a trailing edge outboard (TEO) flap, and a trailing edge inboard (TEI) flap. The wing control surfaces are constructed of S2-glass skins with an internal honeycomb core. The control surfaces are attached to the main wing structure through hydraulic actuators and hinge lockouts. As shown in figure 1, each surface uses two lockouts except the TEO flap. Hinge locks were required due to underpowered actuators for the hinge moments expected on the control surfaces.

Figure 3 shows a schematic of the VSS model configuration and instrumentation layout. The model was mounted to the tunnel sidewall turntable through a five-component balance used for measuring aerodynamic loads. The turntable was used to set model angle-of-attack, $\alpha$, which was measured with an Allied Signal Model 700 Q-Flex accelerometer mounted just aft of the center of rotation in the fuselage. Fifteen Model V352B22/015 PCB Piezotronics accelerometers were used to monitor the dynamic motions of the wing and flaps as shown in figure 3. Bending and torsion strain gages were applied to the main wing at the root and 2/3-span (near the wing fold span station of an F/A-18) to determine the localized loads on the model. Three rows of orifices on the upper and lower surface of the fuselage were used to measure the static pressures on the fairing standoff. Two optical-based systems were used to measure the deflection of the wing and control surfaces under aerodynamic load. These were the Projection Moiré Interferometry $(\mathrm{PMI})^{8}$ and Video Model Deformation (VMD) ${ }^{9}$ systems.

Rotary potentiometers were attached to each actuator to measure the flap deflection angles, $\delta$. Due to the potentiometers' limited resolution within the deflection angle range tested, the flap deflections had to be measured using other transducers. A calibrated inclinometer was used to change the flaps to the desired deflection angles, but the local main wing angle was not measured with the inclinometer. The inclinometermeasured deflection angles were compared to the angles measured by the VMD system for each control surface. Since the VMD deflection angle dataset was a more direct and complete measurement of the flap deflections relative to the main wing, the measured flap angles from the VMD System were used to calculate the control surface derivatives. ${ }^{10}$

Improperly fabricated solder joints in the hydraulic tubing for the actuators and hinges were discovered during checkout prior to wind-tunnel testing. These solder joints were not easily repairable and the hydraulic lines to the actuators and hinges had to be disconnected. Without the ability to remotely actuate the flaps and hinge lockouts, the control surfaces were manually adjusted and the hinges mechanically locked in place.

Early in testing, the LEI flap departed the model at the highest test load condition. Prior to the flap failure, angle of attack polars were run to measure the loads on the baseline configuration and clear the model throughout the test envelope. During the subsequent run to acquire a baseline dataset, the LEI flap failure occurred at a constant and nearly unloaded angle of attack. Post-run analysis of the VMD data on the LEI flap showed flap deterioration during the angle of attack polar runs and the hinge-line strength compromised throughout the baseline test run. A detailed discussion of the failure incident is given in reference 10 . The flap was replaced by retrofitting a flap used for fabrication concept verification and proof loading, but the replacement flap could not be deflected and no data was acquired with the LEI flap deflected.

\section{Model Design Considerations}

\section{Maximum Load Condition}

The design load condition corresponded to the maximum test condition of Mach 1.2, a dynamic pressure of $350 \mathrm{psf}$, and $+5^{\circ}$ angle of attack. The wing pressure distribution corresponding to the maximum test condition with no control surfaces deflected was calculated using the MSC NASTRAN AERO II package (ZONA51 method) ${ }^{11}$ on the full-scale finite element model (FEM). Figure 4 shows this pressure distribution scaled and applied to the model-scale FEM as an element variable pressure load. Integrating this pressure distribution over the model planform area resulted in a model-scale load of 1624 lbs.

The scaled pressure distribution was discretized to facilitate the sizing and stress calculations for various components. This discretization resulted in loads for the control surfaces of $727 \mathrm{lbs}, 421 \mathrm{lbs}, 160 \mathrm{lbs}$, and 


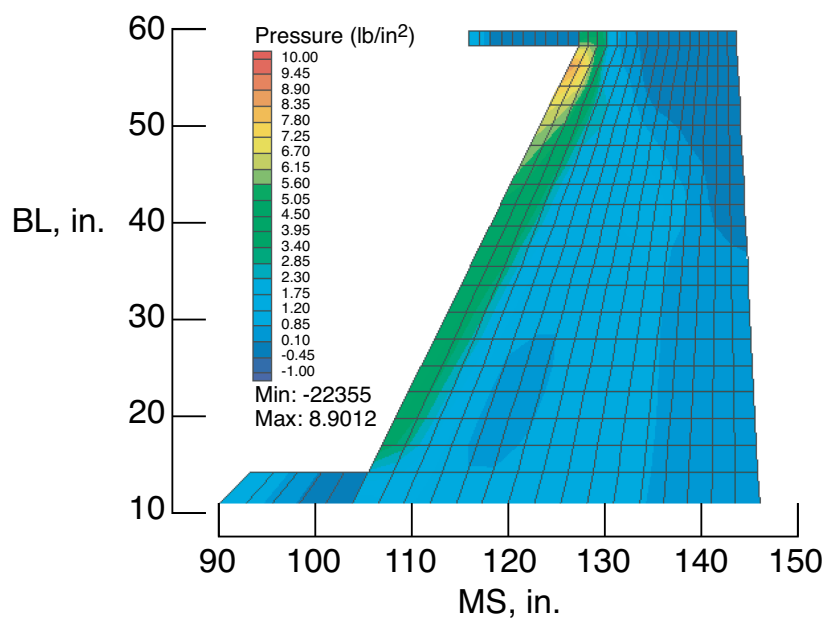

Fig. 4 Wing model pressure distribution at $M=$ 1.2, $q=350$ psf, $\alpha=5^{\circ}$.

$25 \mathrm{lbs}$ for the LEI, LEO, TEI, and TEO, respectively. The load on the main wing was $780 \mathrm{lbs}$; therefore, the simplification of the model-scale pressure distribution represents a total wing load of $2113 \mathrm{lbs}$. This is a conservative simplification since the original pressure distribution results in a total wing load of only 1624 $\mathrm{lbs}$, and the $2113 \mathrm{lbs}$ represents a load that is $30 \%$ higher. The higher load is due to areas of overlap between the main wing and the control surfaces.

The hinge moment requirements represent the worst case load conditions for all control surfaces. These moments were calculated using the as-built finite element model, with total values on each control surface of 1811 in-lbs, 497 in-lbs, 927 in-lbs, and 89.3 in-lbs corresponding to the LEI, LEO, TEI, and TEO control surfaces, respectively.

\section{VSS Effectiveness Definition}

A definition of the VSS effectiveness is required to quantify the ability of the VSS to alter the structural characteristics of the model. At a given load, VSS effectiveness is defined by the following equation:

$$
E f f_{V S S}=\frac{\left(\theta_{V S S \text { horiz }}-\theta_{V S S \text { vert }}\right)}{\theta_{V S S \text { vert }}}
$$

where $\theta$ is the measured wing tip twist angle at a given load and VSS orientation.

\section{VSS Design}

Zona Technologies, Inc. conceived an initial VSS concept wing with a sufficiently low torsional stiffness that allowed an ample range for VSS to apply postreversal control. This initial concept and the design load case were transferred to Dynamic Engineering Inc. (DEI) for the design and fabrication of a windtunnel model. DEI designed the initial model concept as a simplified model with a cantilevered root attachment. This design resulted in a VSS effectiveness of $13.39 \%$. Zona optimized the DEI design using the ASTROS* ${ }^{*}$ software package ${ }^{12,13}$ which roughly doubled the wing stiffness of the DEI design and resulted in a change in the VSS effectiveness of $11.98 \%$. When the modified wing design was realistically attached to the fuselage through a root block which was softer than the idealized cantilevered attachment, the VSS effectiveness fell to $8.23 \%$.

This modified design concept was not feasible to test because the wing structure failed to meet the strength requirement criteria for testing in the TDT. The strength criteria requires a factor of safety of four on the yield stress of any component, so the analysis had to show the model would not yield under loads up to four times the maximum load condition plus the $30 \%$ due to the conservative load simplification referred to above. Adjustments to more accurately model the physical article and make the design possible to test further reduced the VSS effectiveness to $7.2 \%$. Finally, a more detailed finite element model was developed to more accurately predict the stress levels in the wing structure and include the balsa airfoil covering. This higher fidelity model showed an increased torsional stiffness in the structure that decreased the VSS effectiveness to its final analytical value of $4.08 \%$. The effectiveness of a VSS concept on a flight vehicle could be greater since the factor of safety for such vehicles is usually much less than four and the wing could be more flexible relative to the spar.

\section{Model Analysis}

DEI furnished detailed MSC NASTRAN ${ }^{14}$ FEMs of the left wing and tip launcher. All the analytical predictions were performed with the left side of the model and the results converted to the proper sign for comparison with the wind-tunnel model. Figure 5 shows the metal components of the wing core with the VSS in the horizontal position. A separate FEM was furnished for the VSS in the vertical position. The wing FEM was intended for stress, vibration, flutter, and aeroelastic trim analyses. Because of the importance of demonstrating the wing would meet the strength requirements, the wing FEM incorporated numerous layers of solid elements so that the stresses resulting from trim analyses could be calculated in sufficient detail.

NASA assembled the wing FEM with an existing FEM of the fuselage and empennage and added simple spring elements to represent the balance. Also added was a NASTRAN aerodynamic model adapted from the AAW flight vehicle aerodynamic model (see figure 6 ). Steady and unsteady aerodynamics were calculated using the Doublet Lattice method for subsonic conditions, and the ZONA51 method for supersonic conditions.

Vibration, flutter and aeroelastic trim analyses were performed. In general, the FEM was more flexible than the actual structure, which is not unusual for aeroelastic models, and provides for conservative re- 


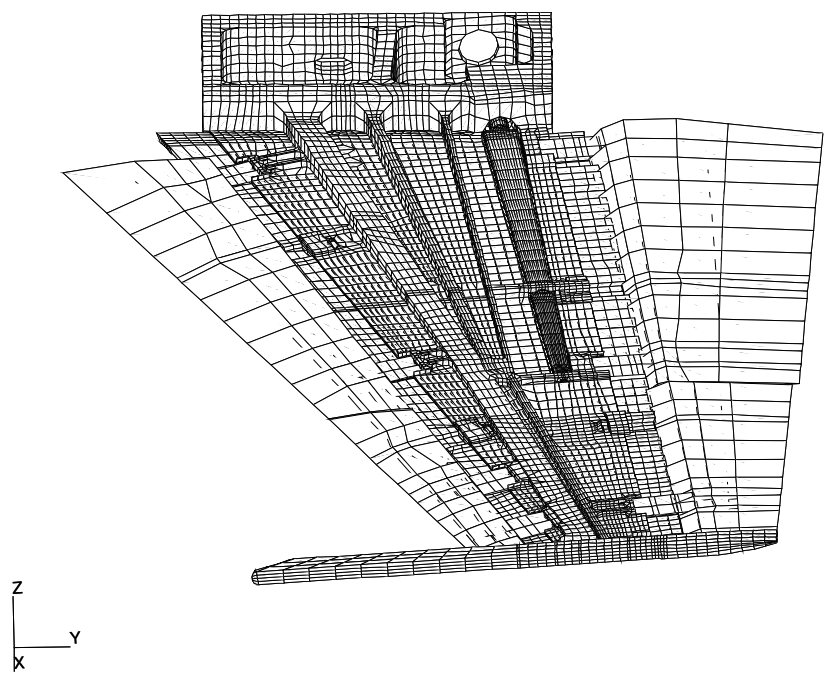

Fig. 5 Finite element model of wing and tip launcher with the VSS in the horizontal position.

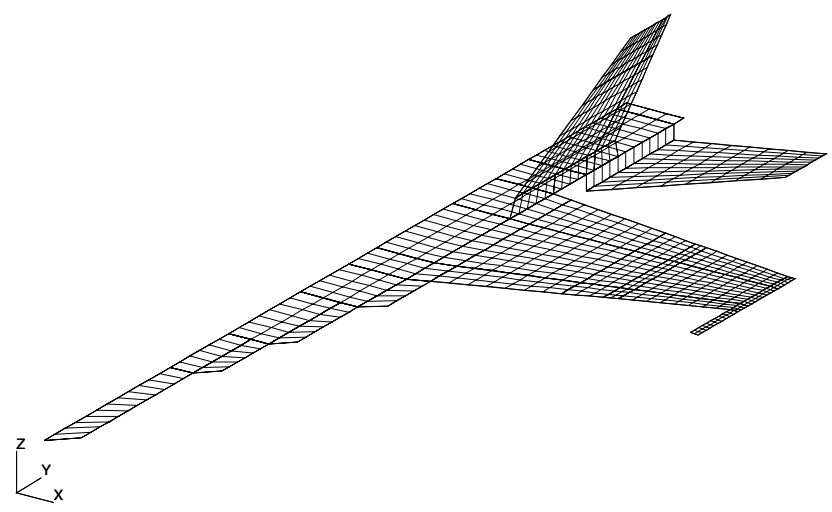

Fig. 6 Aerodynamic box layout for the flutter and trim analyses of the VSS model.

sults for safety issues such as stress and flutter. In this case, the major contributor to the difference in stiffness between the FEM and wind-tunnel model was the fiberglass bonded to the wing surface, which was not modeled in the FEM.

\section{Wind Tunnel Test Conditions}

The TDT testing occurred during two separate entries: September 2002 and January 2003. A photo of the model mounted on the TDT sidewall turntable is presented in figure 7 . Test conditions consisted of eight Mach numbers, $M$, at two wind-off total pressure conditions, as well as 16 dynamic pressures, $q$, at Mach numbers of 0.85 and 0.9 between the two total pressures. The total pressure conditions are referred to as the high and low $q$ lines for discussion purposes. The Mach number and dynamic pressure of each test condition are plotted with the TDT operating boundary for R-134a in figure 8. The VSS was rotated from the horizontal to vertical position at each test condition along the high and low $q$ lines. The VSS was in the horizontal position for the points between the high and low $q$ lines and was not rotated. Angle of attack

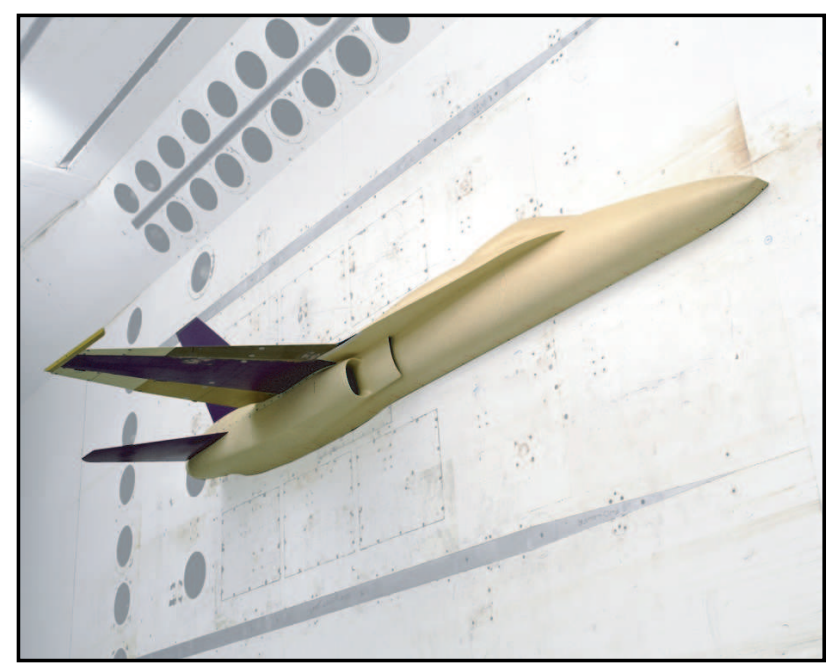

Fig. 7 Photo of VSS model mounted in the TDT.

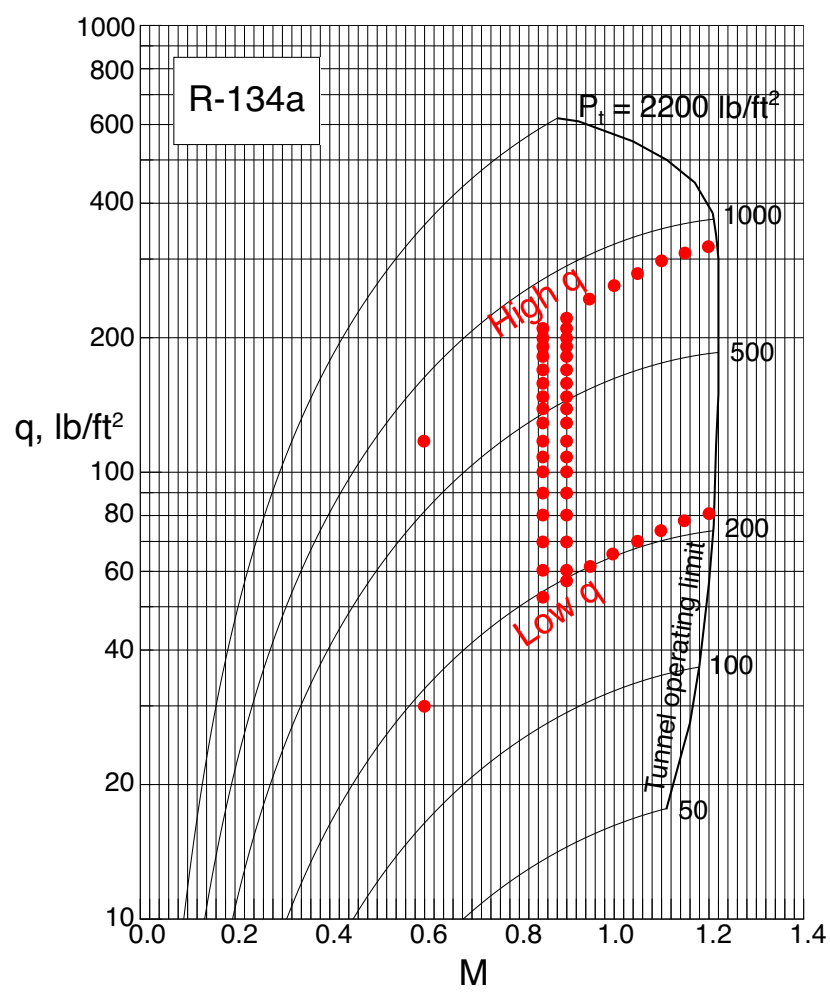

Fig. 8 Conditions within the TDT R-134a operating boundary where data were acquired.

polar data consisting of four to five angles of attack were acquired at each Mach number. Table 1 lists the various flap deflection combinations where data were acquired at each $M, q$, and VSS condition.

\section{Discussion of Results}

The database acquired included the model stiffness and modal data, model deformation data, aerodynamic loads, static control surface derivatives, and fuselage standoff pressure data. This section of the paper presents a preliminary subset of the data. A detailed discussion of the model deformation data is 
Table 1 Mean control surface deflections in degrees as measured by a calibrated inclinometer.

\begin{tabular}{|c|c|c|c|}
\hline Order & $\delta_{T E O}$ & $\delta_{T E I}$ & $\delta_{L E O}$ \\
\hline Tested & \multicolumn{3}{|c|}{ in degrees } \\
\hline 1 & 1.34 & 2.00 & -0.04 \\
\hline 2 & -1.84 & -1.94 & -0.08 \\
\hline 3 & 1.33 & -0.06 & -1.68 \\
\hline 4 & -1.94 & -0.18 & 2.16 \\
\hline 5 & 1.21 & -1.40 & 0.77 \\
\hline 6 & 0.01 & 0.00 & 0.01 \\
\hline
\end{tabular}

presented in reference 10. A description of the data reduction process is discussed first.

\section{Data Reduction}

The balance data were corrected for weight due to angle of attack changes and the wind off loads were removed. The lift and moment coefficients were formulated in the stability axis system; the non-dimensional coefficients were generated using a reference area, $S=$ $1960.4 \mathrm{in}^{2}$, reference semi-span, $b=58.6$ inches, and reference mean aerodynamic chord, $\bar{c}=36.1$ inches. All moments are calculated with respect to the balance center, so no transfer distances were used. Though not included in the data presented in this paper, the loads from the integrated pressures on the fuselage standoff will be used to remove the effects of the standoff on the control coefficients.

The control surface derivatives were calculated using the mean value of the wind-off VMD measurements of the control surface positions. The VMD measurements were corrected for wing shape and angle relative to the measured $\alpha$ of the main wing box. The angles measured wind-off before and after each run had some variability. Error bars were generated for each of the control surface derivatives representing the minimum and maximum values of the measured control surface position, which is the only variation included in the error bars. These error bars are most evident in the LEO flap data in figures $14(\mathrm{c})$ and $15(\mathrm{c})$. Errors associated with each of the measurement systems were examined and determined to be insignificant relative to the uncertainty introduced by the physical change in control surface position.

The force and moment derivatives with respect to angle of attack and control surface deflections were generated assuming linear expressions such as the following were valid.

$$
\begin{aligned}
C_{L}=C_{L_{0}}+C_{L_{\alpha}} \alpha & +C_{L_{\delta_{T E O}}} \delta_{T E O} \\
& +C_{L_{\delta_{T E I}}} \delta_{T E I}+C_{L_{\delta_{L E O}}} \delta_{L E O}
\end{aligned}
$$

At each test condition, the data sets corresponding to all $\alpha$ 's and $\delta$ 's were used and the linear relationships applied, generating as many equations as there were data sets. These equations were rewritten in matrix notation resulting in the following expression.

$$
\left\{\begin{array}{c}
C_{L_{1}} \\
C_{L_{2}} \\
\vdots \\
C_{L_{n}}
\end{array}\right\}=\left[\begin{array}{ccccc}
1 & \alpha_{1} & \delta_{T E O_{1}} & \delta_{T E I_{1}} & \delta_{L E O_{1}} \\
1 & \alpha_{2} & \delta_{T E O_{2}} & \delta_{T E I_{2}} & \delta_{L E O_{2}} \\
\vdots & \vdots & \vdots & \vdots & \vdots \\
1 & \alpha_{n} & \delta_{T E O_{n}} & \delta_{T E I_{n}} & \delta_{L E O_{n}}
\end{array}\right]\left\{\begin{array}{c}
C_{L_{0}} \\
C_{L_{\alpha}} \\
C_{L_{\delta_{T E O}}} \\
C_{L_{\delta_{T E I}}} \\
C_{L_{\delta_{L E O}}}
\end{array}\right\}
$$

The vector on the left hand side consisted of quantities available from the balance data. The matrix containing the measured $\alpha$ 's and $\delta$ 's was also known. The vector of unknowns was obtained by premultiplying the left hand side column vector by the pseudo-inverse of the measured angles matrix. This resulted in a least squares solution for the coefficients. All force and moment derivatives were generated in an identical manner.

\section{Modal and Stiffness Test Results}

Data from the stiffness and ground vibration tests are presented and compared with analyses. Stiffness test measurements showed an increase in the wing bending deflections from the vertical to the horizontal positions of the spar of approximately $14 \%$ just inboard of the wing fold area and about $9 \%$ at the tip. Wing torsional deflections showed a much greater increase inboard of the wing fold of about $22 \%$ and an increase in torsional deflections of roughly $8.5 \%$ at the tip.

Ground vibration tests were conducted on the model using a shaker to apply force excitation to the wing and accelerometers to measure the response over the entire model. Table 2 lists the measured and predicted modal frequencies for the VSS in the vertical and horizontal positions and a description of the corresponding mode shape. In moving the VSS from the horizontal to the vertical position, the frequencies of the wing modes clearly increase. Table 2 also shows the frequencies for the first wing bending and torsion modes are lower for the analysis compared to the measured frequencies, indicating the analytical model is more flexible than the wind-tunnel model.

\section{Lift Curve Slope Results}

Figure 9 compares the values of the predicted lift curve slope, $C_{L_{\alpha}}$, of the wing with the VSS in the horizontal orientation with corresponding measured values. At subsonic speeds, the analysis shows an increase in the $C_{L_{\alpha}}$ when aeroelastic flexibility is included in the calculations versus the $C_{L_{\alpha}}$ for the rigid analysis, and a decrease in $C_{L_{\alpha}}$ for $M>1$. The overall trends of the lift curve slope with Mach number are similar to the measured subsonic and supersonic values, however the experiment shows the onset of compressibility effects at a lower Mach number than the analysis.

Figure 10 shows the measured lift curve slopes for both orientations of the VSS over a Mach number range of 0.6 to 1.2 . The horizontal orientation of the 
Table 2 Measured and predicted frequencies with mode descriptions.

\begin{tabular}{|c|c|c|c|c|c|}
\hline & Measured & Frequencies, $\mathrm{Hz}$ & Predicte & requencies, $\mathrm{Hz}$ & \\
\hline Mode & Vertical & Horizontal & Vertical & Horizontal & Description \\
\hline 1 & 13.47 & 12.62 & 12.11 & 11.60 & First Wing Bending \\
\hline 2 & 17.68 & 17.69 & 16.84 & 16.67 & non-wing (Balance Pitch) \\
\hline 3 & 30.84 & 30.17 & 26.36 & 26.40 & First Wing Torsion \\
\hline 4 & 34.80 & 34.80 & & & non-wing (Vertical Tail) \\
\hline 5 & 36.67 & 36.31 & & & non-wing (Horizontal Tail) \\
\hline 6 & 45.04 & 43.55 & 40.39 & 40.71 & Second Wing Bending \\
\hline 7 & 51.00 & 51.00 & & & non-wing (Vertical Tail) \\
\hline 8 & 57.92 & 57.06 & 49.31 & 52.54 & Second Wing Torsion \\
\hline 9 & 63.46 & 63.38 & & & non-wing (Horizontal Tail) \\
\hline 10 & 66.11 & 66.05 & & & non-wing (Fuselage Twist) \\
\hline 11 & 70.83 & 70.26 & 71.26 & 73.93 & TEO, Tip Launcher Bending \\
\hline 12 & 76.99 & 76.81 & & & non-wing \\
\hline 13 & 88.34 & 87.56 & & & TEO, TEI \\
\hline 14 & 94.17 & 93.41 & & & Complicated \\
\hline 15 & 99.75 & 98.78 & & & Third Wing Bending \\
\hline
\end{tabular}

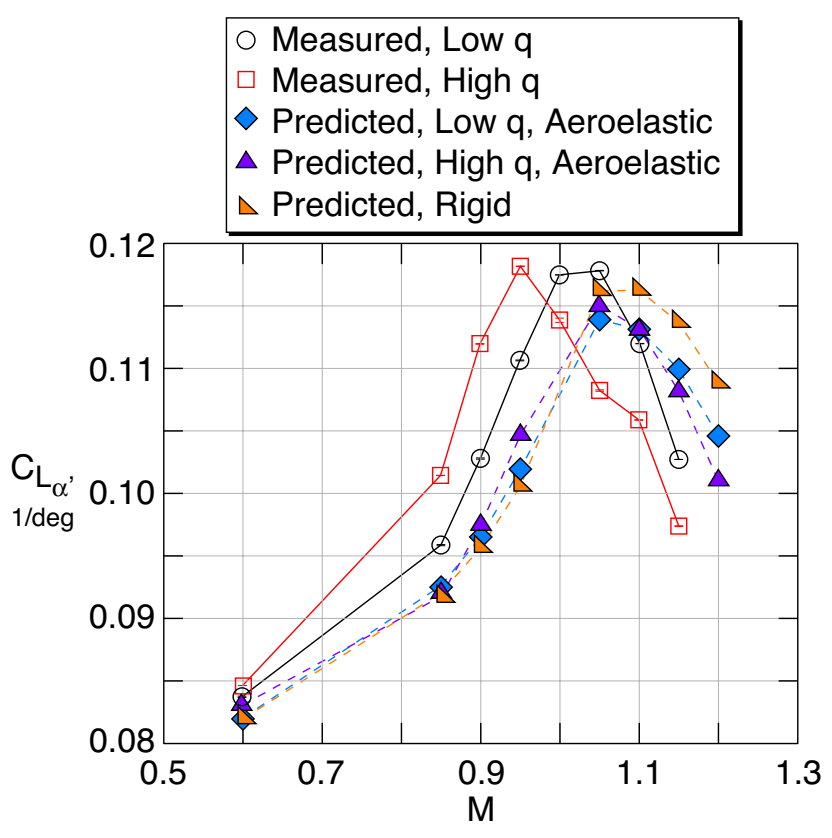

Fig. 9 Comparison of measured and predicted lift curve slope for VSS in horizontal orientation.

VSS shows a decrease in $C_{L_{\alpha}}$ when compared to the stiffer, vertical orientation. The differences in $C_{L_{\alpha}}$ ar larger in the transonic and supersonic speed regimes than they are in the subsonic regime.

\section{Fuselage Standoff Effects}

Static pressure measurements on the fuselage standoff were measured to quantify standoff and tunnel wall boundary layer effects on the aerodynamic loads and control derivatives. Figure 11 shows example pressure distributions for a subsonic and supersonic test condition at $0^{\circ}$ angle of attack. In both figures 11(a) and 11 (b), the pressure rise on the upper surface due to the cockpit and pressure drop on the lower surface due to

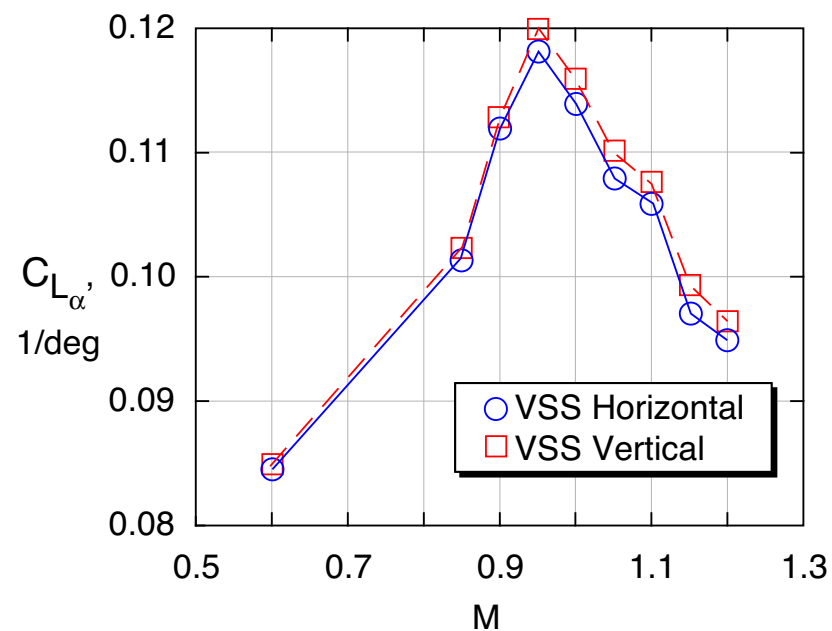

Fig. 10 Effects of VSS orientation on the measured lift curve slope with no control surfaces deflected.

the flow through nacelle are very apparent.

Figures 12(a) and 12(b) show the calculated lift and pitching moment coefficients for the fuselage standoff at $\alpha=0^{\circ}$ and Mach numbers from 0.6 to 1.2 . These coefficients were calculated by integrating the measured pressures over the standoff upper and lower surfaces. Figures such as $12(\mathrm{a})$ and $12(\mathrm{~b})$ will be used in the future to correct the measured aerodynamic loads used in the calculation of the control surface derivatives. However, to date, the corrections have not been included in the data. These corrections for the measured aerodynamic loads were small at low subsonic speeds, but grew larger through the transonic speed regime. This can be seen in figures $12(\mathrm{a})$ and 12 (b) by the changes in lift and pitching moment coefficients from $M=0.9$ to $M=1.1$. 


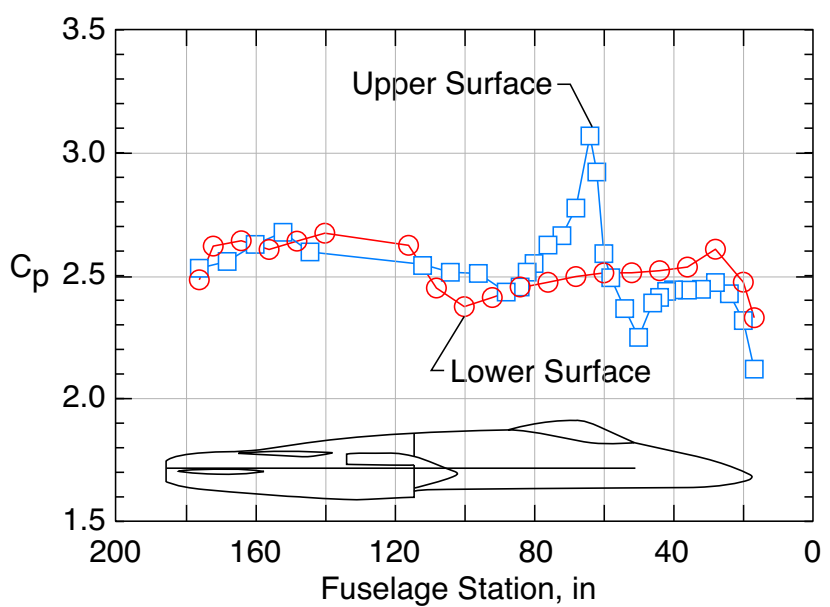

a) $M=0.8485, q=212.87 \mathrm{lbs} / \mathrm{ft}^{2}, \alpha=0^{\circ}$.

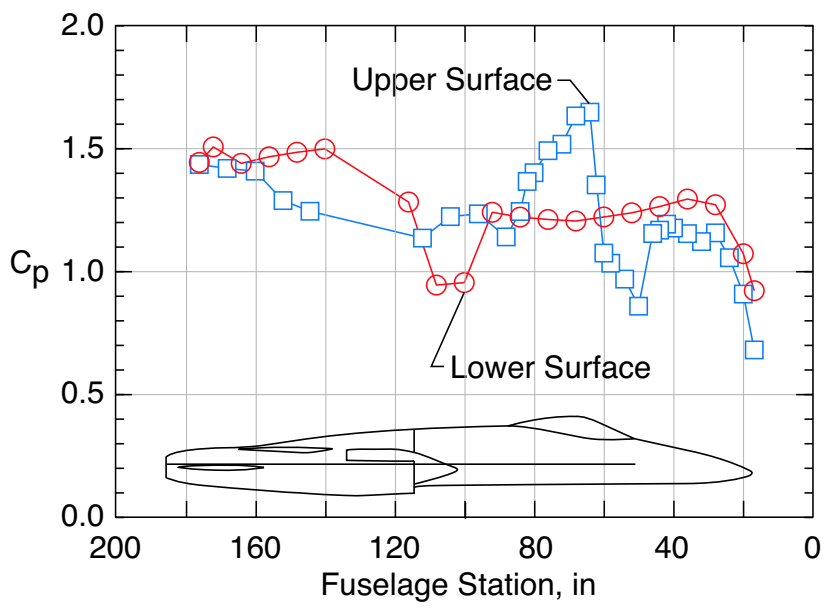

b) $M=1.1997, q=324.85 \mathrm{lbs} / \mathrm{ft}^{2}, \alpha=0^{\circ}$.

Fig. 11 Static pressure distributions on the fuselage standoff.

\section{Trailing-edge Control Surface Effectiveness at Constant Mach Number}

Diminished control surface effectiveness generally occurs for trailing edge control surfaces on aft-swept wingsas dynamic pressure increases. Classical control surface reversal on a typical section is thoroughly discussed in many textbooks. It is defined by deflection of the control surface producing a response opposite to the intended response brought about through aeroelastic deformation. ${ }^{15}$ As the dynamic pressure increases, the control derivatives approach zero and can eventually change sign, indicating reversal. Flow separation over the control surface is also generally known to diminish control surface effectiveness. Permitting the wing to have large amounts of aeroelastic twist generally degrades the effectiveness of trailing-edge control surfaces in terms of rolling moment and lift generation.

The aeroelastic control surface effectiveness is most easily examined using data obtained at a constant Mach number and varying the dynamic pressure, thereby eliminating Mach number effects. Examina-

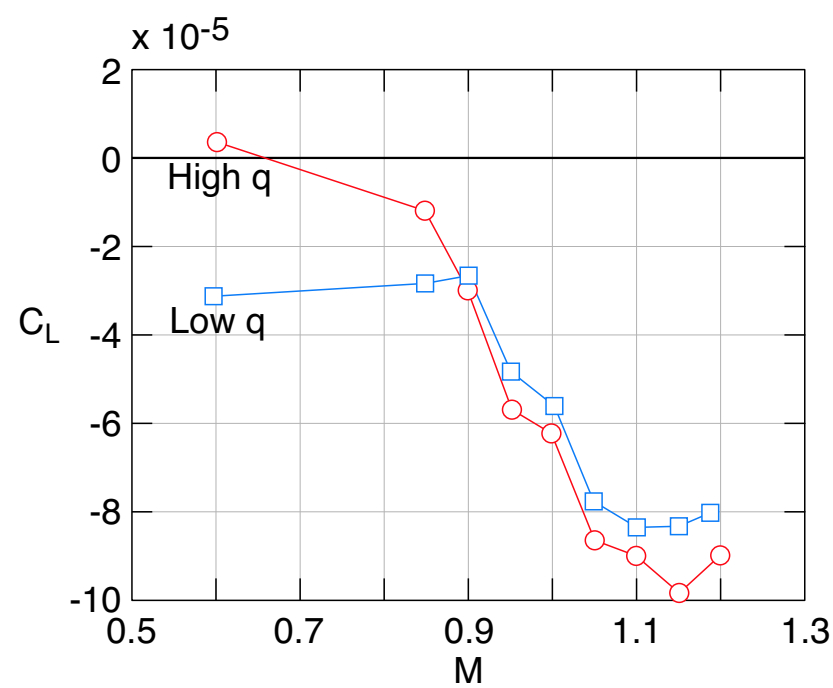

a) Lift coefficient.

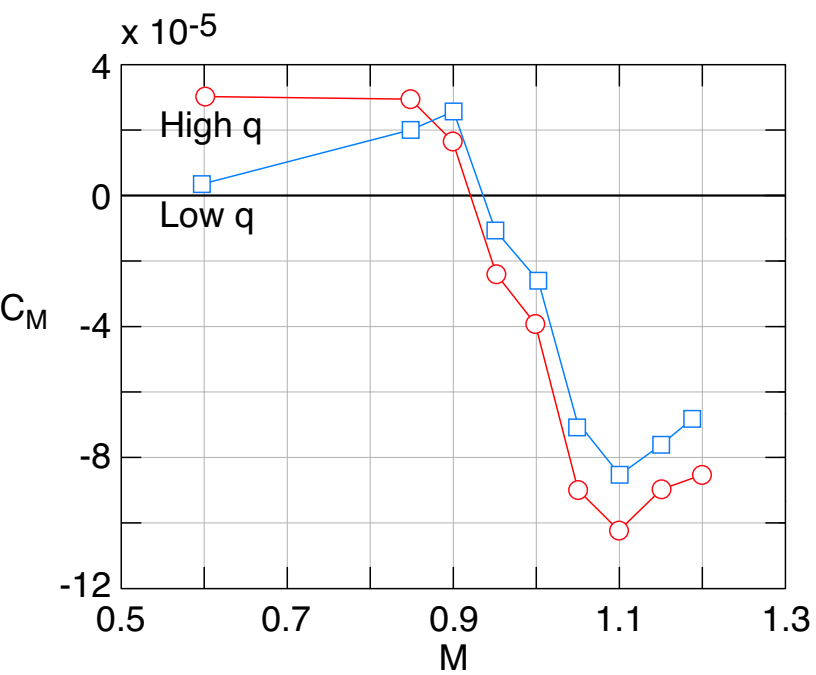

b) Pitching moment coefficient.

Fig. 12 Variation of lift and pitching moment coefficient for the fuselage standoff.

tion of the data as a function of dynamic pressure focuses on the coupling of the structural response and a given applied pressure distribution. Constant Mach number data is also important since examining the derivative as a function of Mach number will not yield a condition at which the control surface will reverse, nor can it be used to estimate the control surface effectiveness at other conditions.

At $M=0.85$ and $M=0.9$, two sets of data were acquired for various dynamic pressures. These data sets were acquired during testing at constant Mach number while varying total pressure. The VSS was in the horizontal position during the total pressure changes. Trailing-edge control surface effectivenesses in roll, $C_{\ell_{\delta}}$, are shown in figure 13 . The data indicate that the control surfaces are less effective at the higher Mach number. The trends with dynamic pressure 


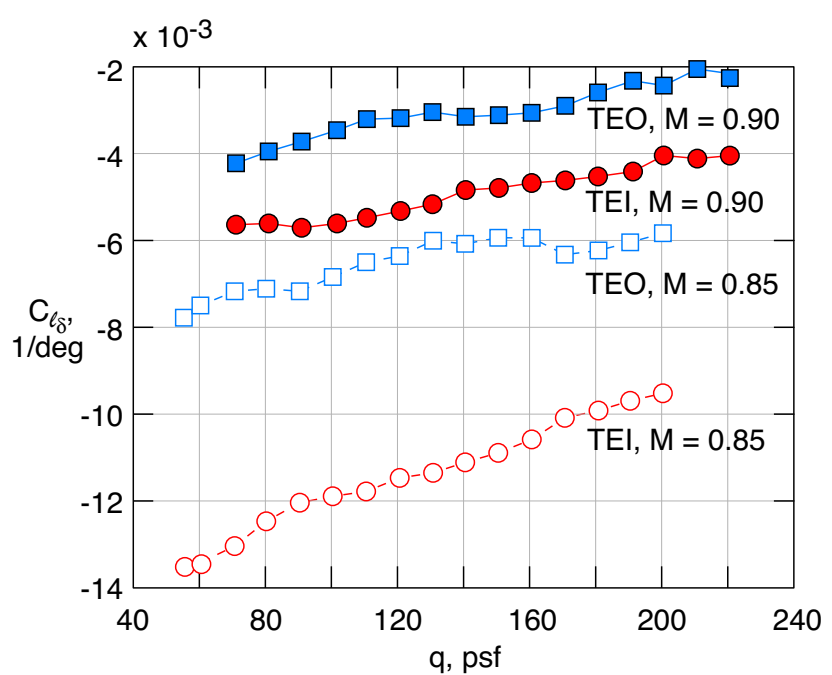

Fig. 13 Trailing edge control surface reversal trends with VSS in the horizontal orientation.

show the tendency of the trailing-edge control surfaces to lose their effectiveness. Control surface reversal was not achieved during the test due to the load limits on the model. Extrapolation of the data in figure 13 using linear regression produces reversal dynamic pressures for the TEO control surface of $573 \mathrm{lbs} / \mathrm{ft}^{2}$ at $M=0.85$ and $370 \mathrm{lbs} / \mathrm{ft}^{2}$ at $M=0.9$. The TEI control surface trends show that reversal would occur at a dynamic pressure of approximately $545 \mathrm{lbs} / \mathrm{ft}^{2}$ at $M=0.85$ and $528 \mathrm{lbs} / \mathrm{ft}^{2}$ at $M=0.9$.

\section{Comparison of Measured and Predicted Control Surface Effectiveness}

Comparisons of the measured and predicted control surface effectivenesses in roll, with the VSS in the horizontal position, are shown in figure 14. Examining the rigid analysis for the trailing-edge control surfaces represented by the closed right triangle shows the effect solely of the change in pressure distribution for the different Mach numbers on $C_{\ell_{\delta}}$ due to the trailing edge control surfaces since the data is independent of dynamic pressure. Figures $14(\mathrm{a})$ and 14(b) show that both trailing edge control surfaces exhibit the same trends with increasing Mach number: subsonically, they are more effective in roll approaching sonic speed and supersonically they become less effective.

Examining the analytical predictions with aeroelastic flexibility at subsonic speeds, represented by the closed diamond and isosceles triangle symbols in figures 14(a) and 14(b), the trailing-edge control surfaces are less effective compared to the rigid predictions. The effects of increased dynamic pressure are also apparent in the comparison of the aeroelastic analysis between the low and high $q$ lines. For the high $q$ aeroelastic analysis, the trend with Mach number differs from the low $q$ and rigid analysis at subsonic speeds in the control surfaces are less effective in roll as Mach number increases.

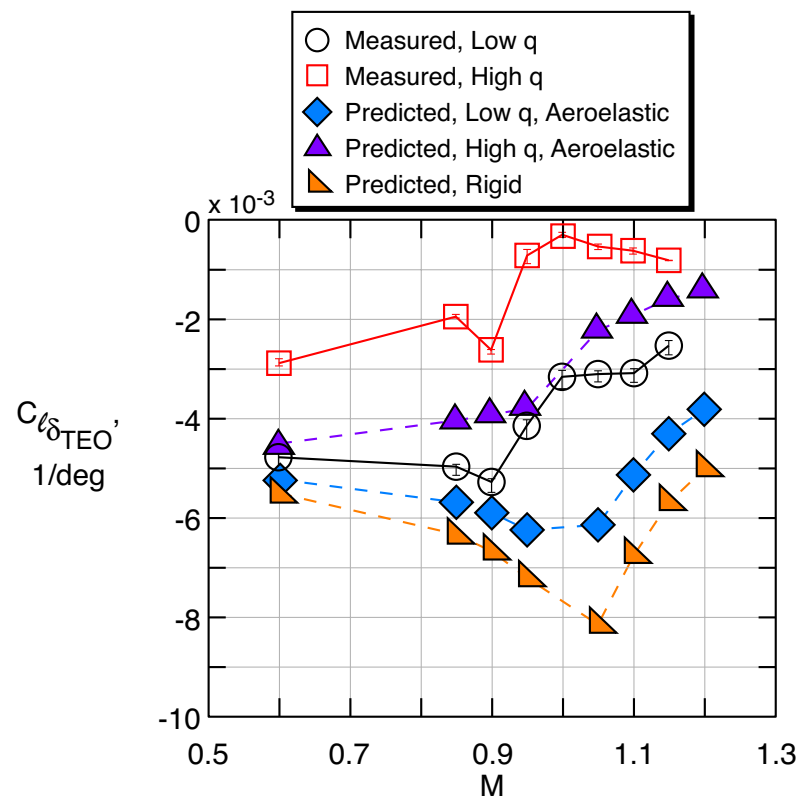

a) Trailing-edge outboard flap.

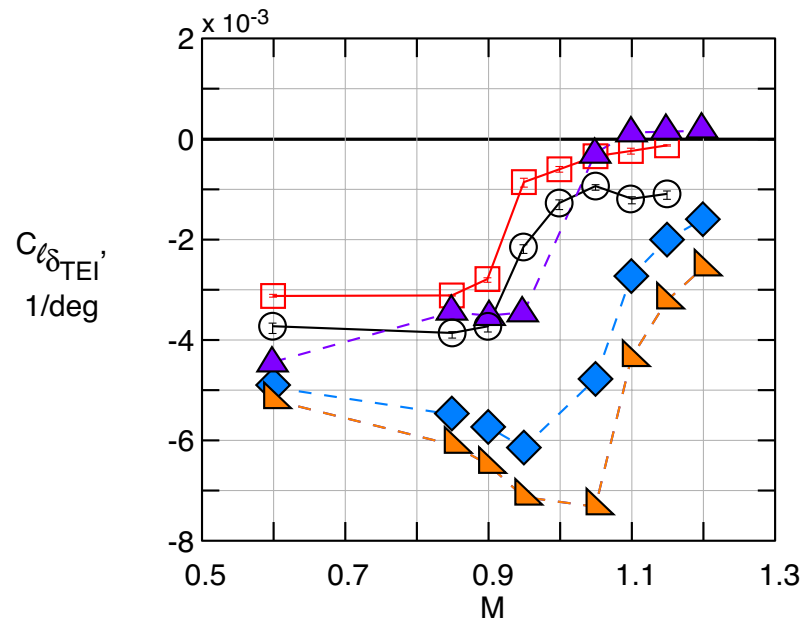

b) Trailing-edge inboard flap.

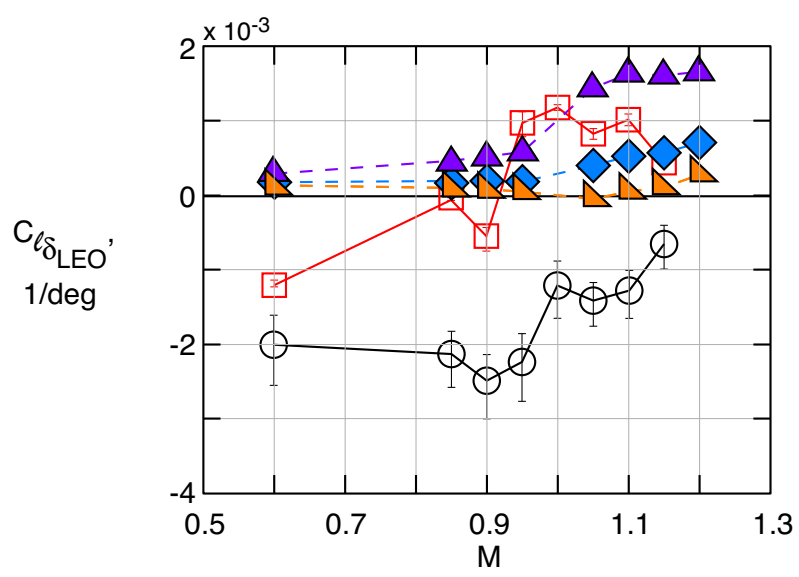

c) Leading-edge outboard flap.

Fig. 14 Comparison of the measured and predicted control surface effectiveness with the VSS in the horizontal orientation. 
Comparisons of the measured and predicted values of $C_{\ell_{\delta}}$ for the trailing-edge control surfaces show the overall trends look similar with Mach number. The experiment generally shows less control effectiveness than the analysis, which is most likely due to flow separation over the control surfaces as discussed previously, which is not accurately modeled in the analysis. For the high $q$ case analyzed and tested, the subsonic trend has clearly reversed direction. As Mach number increases, the control surfaces are shown to be less effective in roll. The effect of flexibility appears more dominant in the measured data for the TEO flap. This is shown by the larger change caused by going from the high $q$ case to the low $q$ case in figure 14(a). The change in the experimental data is significantly greater than the change observed in the analysis. For the trailing-edge inboard flap data presented in figure $14(\mathrm{~b})$, the wind-tunnel model data remains almost constant with Mach number in the subsonic region and appears to be less sensitive to dynamic pressure. Finally, the abrupt change in slope in $C_{\ell_{\delta}}$ occurs at lower Mach numbers.

Examining the leading-edge control surface effectiveness plotted in figure 14(c) shows the sign for the measured $C_{\ell_{\delta_{L E O}}}$ is opposite that of the predicted. The elastic axis position of the outboard wing section causes the derivatives for this control surface to be sensitive to the modeled elastic axis location. A slight misalignment of the elastic axis in this region can result in the incorrect sign on the control derivative for the comparison between the analysis and the experiment for the VSS. The rigid analysis shows little variation in control effectiveness as Mach number changes, but the inclusion of aeroelastic flexibility increases the control effectiveness as Mach number increases. Finally, the measured high $q$ case shows the LEO flap roll effectiveness changes sign between $M=0.9$ and $M=0.95$.

\section{Effect of VSS Orientation on Control Surface Effectiveness}

Figure 15 shows the effect of the VSS orientation on $C_{\ell_{\delta}}$, for a range of Mach numbers from 0.6 to 1.2 . The data presented is experimental only, with no comparison with analysis. The open symbols represent the horizontal orientation of the VSS and the closed symbols are used for the stiffer, vertical orientation. The data for high and low $q$ cases are also plotted to show the effects of dynamic pressure on the VSS effectiveness. For $C_{\ell_{\delta_{T E O}}}$ in figure $15(\mathrm{a})$, the effects of the stiffer orientation of the VSS are greater in the subsonic speed regime than in the supersonic speed regime. At supersonic speeds, the effects of the VSS are less apparent.

Figures 15(b) and 15(c) show the effects of the VSS orientation on $C_{\ell_{\delta}}$ for the other two control surfaces. For the TEI flap in figure 15(b), the horizontal ori-

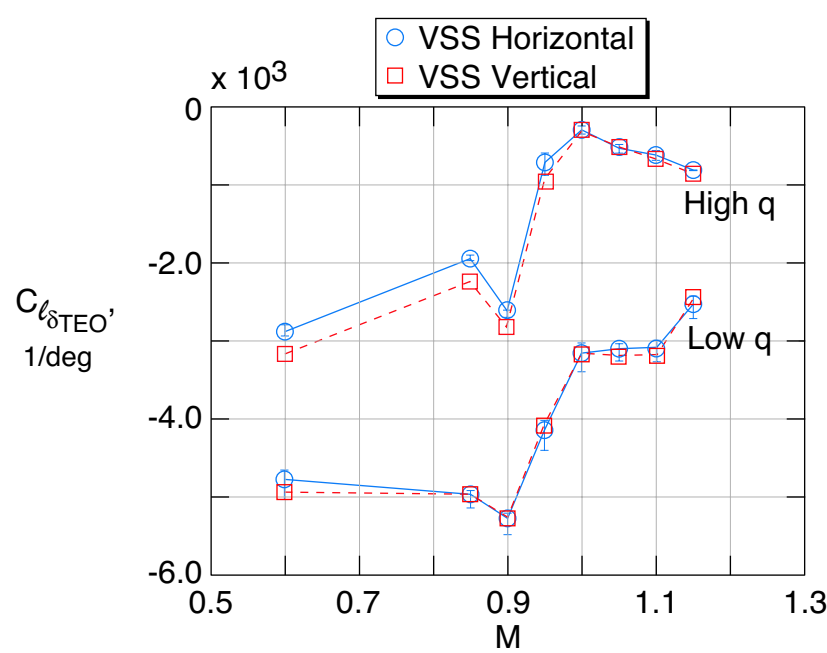

a) Trailing-edge outboard flap.

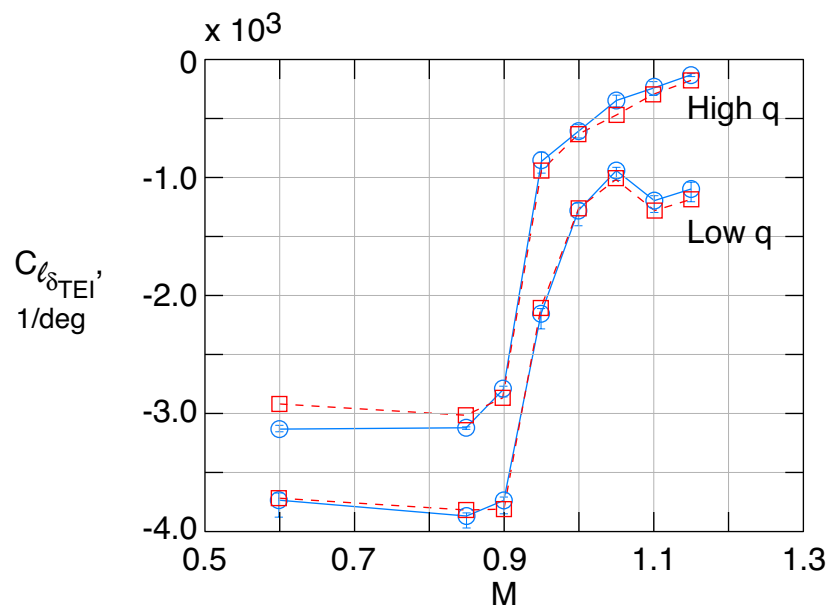

b) Trailing-edge inboard flap.

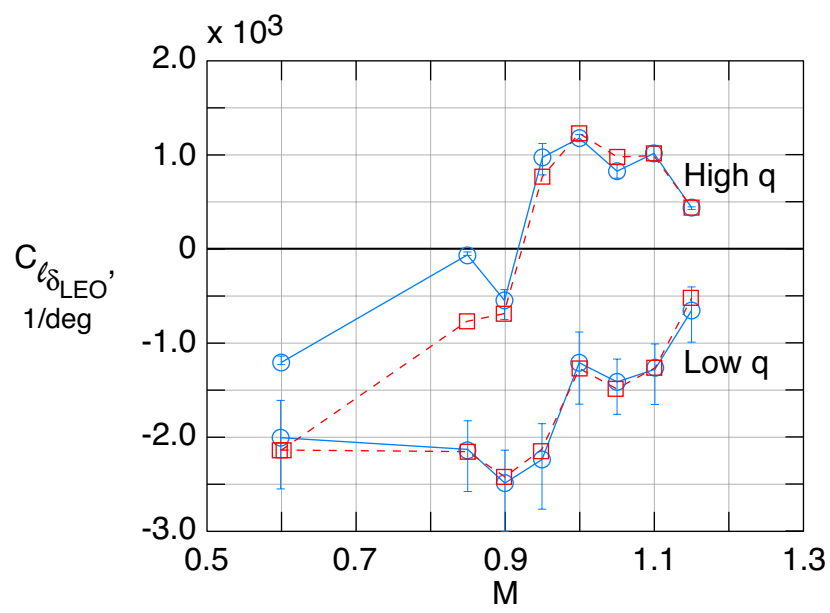

c) Leading-edge outboard flap.

Fig. 15 Effect of VSS orientation on control surface effectiveness. 
entation is slightly more effective at subsonic speeds, becoming less effective than the vertical orientation near $M=0.9$ and above. For the LEO flap (figure $15(\mathrm{c}))$, the effects of the VSS in the low $q$ case are not obvious, but the vertical orientation of the VSS increases the control surface effectiveness at subsonic speeds up to a Mach number of 0.9 . The high $q$ case shows the control surface effectiveness changing sign just above $M=0.9$, with the VSS orientation providing a small effect. All three control surface derivatives are more effective in the low $q$ cases when compared to the high $q$ cases. The data show the effects of the VSS on control surface effectiveness in roll were mixed, though some effect is present.

\section{Concluding Remarks}

A Variable Stiffness Spar (VSS) concept of varying the structural stiffness of the wing and employing multiple leading- and trailing-edge control surfaces was tested in the NASA Langley Transonic Dynamics Tunnel (TDT). A major wind-tunnel model design challenge was the much larger static loads on the model compared to a typical aeroelastic wind-tunnel model designed to address dynamic aeroelastic phenomena. These greater loads had a significant impact on the VSS effectiveness because the model was much stiffer than desired due to the strength requirements.

A detailed structural analysis model was developed and analyzed to show that the wind-tunnel model met the required strength criteria for testing in the TDT. This analytical model was also used to predict the aerodynamic loads and the effectiveness of each control surface in producing rolling moments through an aeroelastic trim analysis. The results of the analysis are compared to the measured results from the wind-tunnel test. The predicted modal frequencies were lower than the measured frequencies, suggesting the analytical model was more flexible than the windtunnel model. As expected, the analysis over predicts the effectiveness of the trailing edge control surfaces when compared to the experiment.

The database of results from tests on the windtunnel model include stiffness and modal data, model deformations, aerodynamic loads, control surface derivatives, and fuselage pressure data. The results show the effect of the VSS orientation on the stiffness and frequency data, the lift curve slope, and the control surface derivatives. The VSS orientation shows a larger effect on $C_{L_{\alpha}}$ in the transonic and supersonic speed regimes than in the subsonic regime. Though trailing-edge control surface reversal was not achieved experimentally, extrapolation of the data suggests that reversal would occur for the TEO flap at a much lower dynamic pressure at $M=0.9$ than at $M=0.85$. The VSS effects on control surface derivatives were only apparent at subsonic conditions with the LEO control surface showing the largest effect.
The difficulties discussed in the design, fabrication, and testing of the wind-tunnel model and the performance of the VSS in altering the aeroelastic characteristics of the wing point to the need for development of improved methods for design and construction of static aeroelastic models.

\section{References}

${ }^{1}$ Chen, P. C., Liu, D. D., Sulaeman, E., Tang, L., Heeg, J., Florance, J. R., Spain, C. V., Ivanco, T. G., Wieseman, C. D., Burner, A. W., Barrows, D., and Lively, P. S., "Development of a Variable Stiffness Spar (VSS) Technology for Aircraft Maneuver Enhancement," Tech. rep., April 2004, To be published as a Wright Laboratory Air Force Research Lab Technical Report.

${ }^{2}$ Miller, G. D., "ActiveFlexible Wing (AFW) Technology," Air Force Wright Aeronautical Labs., AFWAL-TR-87-3096, Feb. 1988.

${ }^{3}$ Perry, III, B., Cole, S. R., and Miller, G. D., "Summary of an Active Flexible Wing Program," Journal of Aircraft, Vol. 32, No. 1, Feb. 1995, pp. 10-15.

${ }^{4}$ Pendleton, E., Besette, D., Field, P., Miller, G. D., and Griffin, K., "The Acive Aeroelastic Wing Flight Research Program," AIAA Paper 98-1972, March 1998.

${ }^{5}$ Florance, J. R. and Rivera, Jr., J. A., "Sidewall Mach Number Distributions for the NASA Langley Transonic Dynamics Tunnel," NASA TM 2001-211019, June 2001.

${ }^{6}$ Staff of the Aeroelasticity Branch, Langley Working Paper - The Langley Transonic Dynamics Tunnel, No. LWP-799, NASA Langley Research Center, Hampton, VA, Sept. 1969.

${ }^{7}$ Cole, S. R., Johnson, R. K., Piatak, D. J., Florance, J. P., and Rivera, Jr., J. A., "Test Activities in the Langley Transonic Dynamics Tunnel and a Summary of Recent Facility Improvements," AIAA Paper 2003-1958, April 2003.

${ }^{8}$ Fleming, G. A., Soto, H. L., South, B. W., and Bartram, S. M., "Advances in Projection Moiré Interferometry Development for Large Wind Tunnel Applications," AIAA Paper 1999-01-5598, Oct. 1999, Presented at the SAE 1999 World Aviation Congress and Exposition, San Francisco, CA.

${ }^{9}$ Burner, A. W. and Liu, T., "Videogrammetric Model Deformation Measurement Technique," Journal of Aircraft, Vol. 38, No. 4, July 2001, pp. 745-754.

${ }^{10}$ Spain, C. V., Heeg, J., Ivanco, T. G., Barrows, D. A., Florance, J. R., Burner, A. W., Demoss, J., and Lively, P. S., "Assessing Videogrammetry for Static Aeroelastic Testing of a Wind-Tunnel Model," AIAA Paper 2004-1677, April 2004.

${ }^{11}$ Rodden, W. P. and Johnson, E. H., MSC/NASTRAN Aeroelastic Analysis User's Guide, v68, The MacNealSchwendler Corporation, 1994.

${ }^{12}$ Chen, P. C., Liu, D. D., Sarhaddi, D., Striz, A., Neill, D., and Karpel, M., "Enhancement of the Aeroservoelastic Capability in ASTROS," STTR Phase I Final WL-TR-96-3119, Sept. 1996.

${ }^{13}$ Chen, P. C., Sarhaddi, D., and Liu, D. D., "Integration of a Steady/Unsteady Wing-Body Module in ASTROS," AIAA Paper 98-1867, April 1998, Presented at the AIAA/ASME/AHS SDM and Adaptive Structure Forum, Long Beach, CA.

${ }^{14}$ Reymond, M. and Miller, M., editors, MSC/NASTRAN Quick Reference Guide, v68, The MacNeal-Schwendler Corporation, 1994.

${ }^{15}$ Bisplinghoff, R. L., Ashley, H., and Halfman, R. L., Aeroelasticity, Dover Publications, Inc., 1996, p. 3. 